\title{
Aspectos radiográficos de periostite ossificante em metatarso de vaca Holandesa
}

\author{
Radiografic aspects of ossifying periostitis in metatarsus of Holstein cow \\ Rodrigo Melo Meneses ${ }^{I}$ Maria Cristina Ferrarini Nunes Soares Hage II \\ Luiz Gonzaga Pompermayer ${ }^{I}$ Luiz Henrique Silva Bulos $^{\mathrm{I}}$
} \begin{abstract}
RESUMO inflamatória extensa, frequentemente oriunda de infecção de tecidos moles adjacentes ao osso afetado, sendo mais proeminente nos bovinos, especialmente em animais jovens. Neste trabalho, é descrito um caso de periostite ossificante no osso metatársico III direito de uma vaca Holandesa após trauma. O diagnóstico foi realizado com base nos achados clínicos e radiográficos e confirmado cirurgicamente.
\end{abstract}

Palavras-chave: reação periosteal, bovinos, fístula, radiografia.

\section{ABSTRACT}

Ossifying periostitis is an extensive inflamatory new bone formation frequently extensive from soft tissue infection next to these bones. It is more observed in young bovines. A case of pos traumatic ossifying periostitis in the right metatarsus of a Holstein cow is described. The diagnosis was made based on clinical and radiographic findings and confirmed cirurgically.

Key words: periosteal reaction, bovine, fistula, radiography.

Lesões do tecido ósseo do metacarpo e metatarso são resultados frequentes da extensão de infecções dos tecidos moles para o periósteo desses ossos (BARGAI et al., 1989). A inflamação do osso não é comum nos animais de produção, exceto quando uma infecção é introduzida, seja por lesões traumáticas, seja por via hematógena (RADOSTITS et al., 2002). Um processo infeccioso produz inflamação que pode comprometer o periósteo, a cortical ou a cavidade medular. O osso reage aos estímulos produzindo proliferações, osteólises ou combinações destas que são reconhecidas radiograficamente. Esses achados se devem ao aumento da atividade osteoblástica ou osteoclástica, ou ainda, de ambas e podem ocorrer em graus variados. As proliferações costumam ser oriundas de estímulos ao periósteo, e a gravidade do estímulo, a anatomia do periósteo e a idade do paciente são variáveis que influenciam o grau de reação periostal (O’BRIEN, 2007).

Como resultado de uma série de alterações ósseas, incluindo osteomielite, trauma e doenças neoplásicas (TONG et al., 2006), o periósteo poderá reagir com a neoformação óssea (KEALY \& McALLISTER, 2005), e o tipo de reação periostal, com frequência, é indicativo do grau de gravidade da lesão que a provoca. Uma reação periostal lisa ou lamelar (casca de cebola), geralmente, indica um processo brando, enquanto um padrão irregular ou interrompido sugere uma lesão agressiva (KEALY \& McALLISTER, 2005). A resposta periostal dos bovinos é geralmente rápida e extensa, especialmente no metacarpo e metatarso e, em poucas semanas, uma neoformação óssea pode dobrar o diâmetro (BARGAI et al., 1989).

A periostite ossificante é uma neoformação óssea inflamatória, na qual o novo tecido ósseo

IUniversidade Federal de Viçosa (UFV), Viçosa, MG, Brasil.

IIDepartamento de Veterinária (DVT), Centro de Ciências Biológicas e da Saúde (CCB), UFV, Av. P. H. Rolfs, s/n, 36570-000, Viçosa, MG, Brasil. E-mail: crishage@ufv.br. Autor para correspondência. 
repousa focalmente ou difusamente ao longo da cortical ou em tecidos moles, quando o periósteo está separado do osso (BARGAI et al., 1989; TONG et al., 2006). É formado em qualquer padrão amorfo, lamelado ou espiculado, podendo aumentar o diâmetro do osso consideravelmente, em razão da irritação crônica do periósteo, podendo ser secundária à lesão crônica aos tecidos moles ou doença óssea concomitante. É mais proeminente nos animais da espécie bovina em comparação às outras espécies, principalmente em animais imaturos (BARGAI et al., 1989).

Em humanos, a periostite ossificante é uma doença caracterizada por osteomielite crônica não supurativa com periostite proliferativa, com ativa proliferação do periósteo e neoformação subperiostal periférica, em razão de uma infecção média prolongada ou irritação sem necrose ou exudato purulento (BELLI et al., 2002). Na literatura ortopédica humana, a periostite ossificante é relatada envolvendo a face anterior da tíbia e também na superfície lateral do corpo da mandíbula, sendo comum em pacientes jovens, por estar relacionada à atividade osteoblástica (BELLI et al., 2002; TONG et al., 2006).

Os sinais clínicos da periostite ossificante consistem em marcante espessamento do membro e consistência firme deste, sendo muitas vezes insensível à palpação, com possibilidade de claudicação, podendo variar amplamente, dependendo da nova formação óssea e da combinação da resposta do periósteo e calcificação dos tecidos moles.

Radiograficamente, a neoformação óssea periostal em padrões isolados ou misto (amorfo, espiculado ou lamelar) é evidente, e a cortical permanece intacta. O novo tecido mineralizado cria enormes massas radiopacas que são fáceis de identificar nas radiografias. Em alguns pacientes como aqueles com um corpo estranho radiopaco, a causa da resposta periostal é facilmente determinada (BARGAI et al., 1989).

Neste trabalho, relata-se o caso de um animal da espécie bovina, fêmea, da raça Holandesa, de pelagem preta e branca, com três anos de idade, pesando $400 \mathrm{~kg}$, que foi atendido no Hospital Veterinário (HOV) da Universidade Federal de Viçosa, em Minas Gerais (MG), apresentando aumento de volume no membro pélvico direito e presença de fístula com secreção purulenta nesse local. Foi realizado o exame clínico mediante os métodos semiológicos clássicos (FEITOSA, 2004).

De acordo com o histórico, o animal havia se ferido há 90 dias na face lateral do membro, sendo tratado pelo proprietário com limpeza do local e aplicação tópica de antibiótico ${ }^{a}$ por aproximadamente 40 dias, havendo cicatrização completa, mas, após 20 dias, observou-se a presença de fístula com secreção purulenta persistindo por um mês.

Ao exame físico, o animal se apresentava em estação, alerta, em bom estado nutricional, sem alterações na marcha e ausência de desidratação, apresentando aumento de volume de consistência firme no terço médio do osso metatársico III direito e fístula na face lateral de aproximadamente $1 \mathrm{~cm}$ de diâmetro, drenando conteúdo purulento. Ao exame radiográfico, observou-se reação periostal intensa da região proximal até o terço médio distal do osso (Figura 1A e B), compatível com o diagnóstico de periostite ossificante, como descrito por BARGAI et al. (1989) e TONG et al. (2006). Além disso, evidenciou-se a presença de uma região radiotransparente, circular, com cerca de $1,5 \mathrm{~cm}$ de diâmetro, proximal ao terço médio do metatarso e voltada à região plantar, caracterizando área de lise, sem evidências de corpo estranho radiopaco. Realizouse exploração cirúrgica e verificou-se a existência de um fragmento ósseo desvitalizado, caracterizando um sequestro ósseo, que estava atuando como corpo estranho e provocando a fistulação, como citado por BARGAI et al. (1989), RADOSTITS et al. (2002), KEALY \& McALLISTER (2005) e O’BRIEN (2007).

Há duas hipóteses plausíveis para a formação do sequestro ósseo nesse caso. A primeira é que ocorreu infecção óssea (osteomielite) contígua ao tecido mole, levando a uma deficiente irrigação de um segmento ósseo, que necrosou e supurou, se soltando como um fragmento no momento da curetagem. A segunda é que pode ter se formado como consequência do trauma inicial em razão da formação de uma esquírola, não identificada ao exame radiográfico prévio. A reação periostal intensa (periostite ossificante) pode, também, ter sido secundária a qualquer das duas hipóteses, osteomielite ou trauma, concordando com as explicações de BARGAI et al. (1989), tendo em vista que a causa primária não foi confirmada por exames complementares (biópsia óssea com cultura para fungos e bactérias, além de exame histopatológico).

O pós-operatório foi realizado por meio de limpeza da ferida com solução fisiológica e lavagem externa com solução antisséptica ${ }^{\mathrm{b}}$. Adicionalmente, foram realizadas três aplicações de antibiótico ${ }^{c}$ na dose de $30 \mathrm{mg} \mathrm{kg}^{-1}$, por via intravenosa, a cada 48 horas, além de três administrações de anti-inflamatório não esteroidal $^{\mathrm{d}}$, sendo a primeira na dose de $10 \mathrm{mg} \mathrm{kg}^{-1} \mathrm{e}$ as últimas na dose de $5 \mathrm{mg} \mathrm{kg}^{-1}$, em intervalos de 24 horas, por via intravenosa.

O animal recebeu alta quatro semanas após a cirurgia, quando a ferida apresentava-se ainda sem completa epitelização, porém com tecido de granulação 

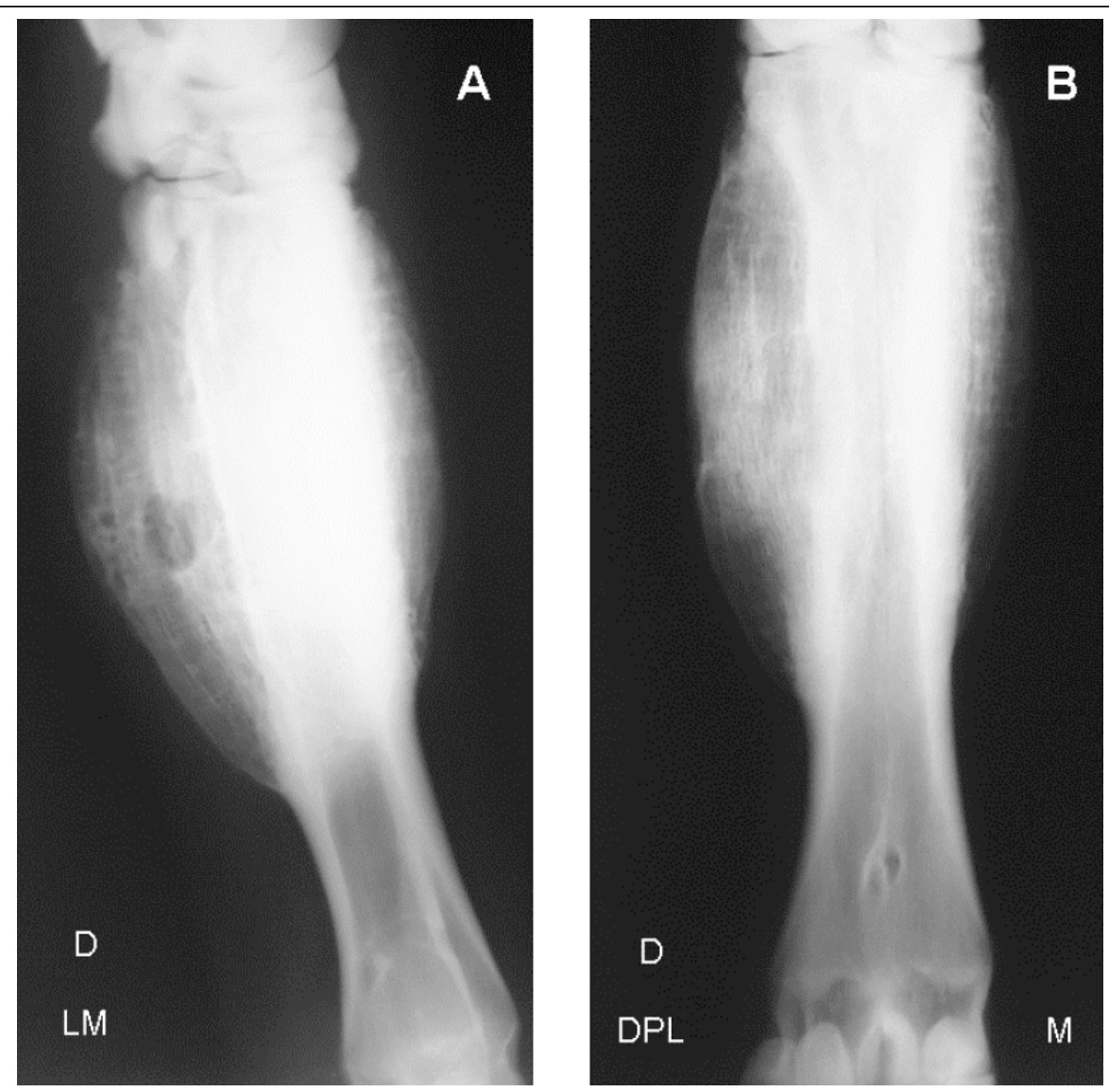

Figura 1A e B - Bovino, fêmea, raça Holandesa, três anos. Imagens radiográficas em projeção lateromedial (LM) e dorsoplantar (DPL) do osso metatársico III direito (D). Observa-se lesão monostótica estendendo-se da região de metáfise proximal à diáfise média distal do osso metatársico III D, apresentando intensa reação periostal do tipo lamelar ( casca de cebola) e levando ao marcante espessamento do diâmetro ósseo. Em região plantar do osso metatársico III na projeção LM, observa-se área circular de lise no osso neoformado. Imagens radiográficas compatíveis com periostite ossificante e trajeto fistuloso. (M) Medial.

preenchendo toda a cavidade formada durante a exploração cirúrgica. Após 30 dias do recebimento da alta, o animal foi examinado na propriedade, apresentando total epitelização e preenchimento da região com tecido de consistência firme à palpação.

Conclui-se que os aspectos radiográficos foram de fundamental importância para o diagnóstico de periostite ossificante, confirmando os achados clínicos e auxiliando na indicação do tratamento cirúrgico do processo inflamatório crônico de origem traumática ou infecciosa. O caso é de interesse porque demonstra a intensa reação periostal que pode ocorrer nos ossos dos animais da espécie bovina frente a agressões. Além disso, é de interesse em razão da escassez de literatura sobre radiologia de bovinos.

\section{FONTES DE AQUISIÇÃO}

a - Terramicina ${ }^{\circledR}$ - Pó solúvel com Antigerm 77 Pfizer Saúde Animal - Av. Monteiro Lobato, 2270, 07190-001, Guarulhos, SP.

b - PVPI Degermante ${ }^{\circledR}$ - Vansil Indústria Comércio e Representações Ltda - Rua João Augusto Cireli, 640, 13690000, Descalvado, SP.

c - Borgal ${ }^{\circledR}$ - Intervet do Brasil Veterinária Ltda - Av. Alfredo Egídio de Souza Aranha, 100, 04791-900, São Paulo, SP.

d - Artridine ${ }^{\circledR}$ - Virbac do Brasil Indústria e Comércio Ltda - Av. Engenheiro Eusébio Stevaux, 1368, 04696-000, São Paulo, SP.

\section{REFERÊNCIAS}

BARGAI, U. et al. Bovine radiology. Ames: Iowa State University, 1989. 198p.

BELLI, E. et al. Sclerosing osteomyelitis of garré periostitis ossificans. Journal of Craniofacial Surgery, v.13, n.6, 
p.765-768, nov. 2002. Disponível em: <http://journal.Iww.com/ jcraniofacialsurgery/toc/2002/1100>. Acesso em: 8 jun. 2009.

FEITOSA, F.L.F. Semiologia veterinária: a arte do diagnóstico. São Paulo: Roca, 2004. 807p.

KEALY, J.K.; McALLISTER, H. Radiologia e ultrasonografia do cão e do gato. Barueri: Manole, 2005. 346p.

O’BRIEN, T.R. Radiologia de equinos. São Paulo: Roca, 2007. 244p.
RADOSTITS, O.M. et al. Clínica veterinária: um tratado de doenças de bovinos, ovinos, suínos, caprinos e eqüinos. Rio de Janeiro: Guanabara Koogan, 2002. 1770p.

TONG, A.C.K. et al. Osteomyelitis with proliferative periostitis: an unusual case. Oral Surgery, Oral Medicine, Oral Pathology, Oral Radiology and Endodontology, v.102, n.5, p.14-19, 2006. Disponível em: $<$ http://dx.doi.org/10.1016/ j.tripleo.2006.03.025>. Acesso em: 9 jun. 2009. doi:10.1016/ j.tripleo.2006.03.025. 